RHS Revista Humanismo

$\mathrm{R} / \mathrm{S}_{\text {y Sociedad }}$

\title{
La tributación en la cultura de los colombianos ${ }^{\Perp}$
}

\author{
Taxation at the culture of Colombians
}

\begin{abstract}
Edgardo Daniel Valero Linero ${ }^{1^{*}}$, Contador Público, Especialista en Tributación, Maestrando en Finanzas.
${ }^{1}$ Docente de la Facultad de Ciencias Empresariales. Corporación Universitaria Remington.
\end{abstract}

(Recibido: 4 de junio de 2014; aceptado: 30 de junio de 2014)

\section{Introducción}

El título del tema no tiene relación con la calidad y profundidad de conocimientos que se pueda tener sobre tributos, se refiere a la concientización, la ética, moral, la concepción y la manera de percibir el aspecto impositivo.

Los colombianos en general no tenemos una adecuada educación y cultura en el campo de los tributos, asumimos una actitud de desagrado y desconfianza cuando se crea o se incrementa un impuesto y cuando es pagado no existe ninguna actitud esperanzadora de beneficio colectivo por parte de quieneslo pagan, incluso consideran que al pagarlos no habrá retribuciones ni inversión social de ningún tipo y estos dineros en gran proporción serán malversados en beneficio de quienes tienen su manejo, con la plena convicción que habrá impunidad.

Nuestra Constitución Nacional que es norma de normas, establece en el artículo 363, los principios del sistema tributario, los cuales, se fundamentan en la equidad, eficiencia y progresividad.
Un alto porcentaje de colombianos considera que estos principios existen solo en el papel, en la constitución, pero en la vida real no existen, por las siguientes razones:

1. No puede haber equidad cuando muchos ciudadanos no pueden satisfacer sus necesidades básicas (Alimentos, vivienda, educación, salud).

2. No puede haber eficiencia, cuando hay corrupción e impunidad.

3. No puede haber progresividad cuando existen impuestos indirectos con tasas tan altas como el impuesto sobre las ventas y donde existe el 4 X 1000.

De este último impuesto se ha beneficiado el sector financiero, uno de los sectores más ricos del país y en Febrero de 2013, el Congreso de la republica propuso destinar un punto para el sector agrícola.

La falta de cultura y conciencia de los colombianos en este campo tiene por lo menos, tres grandes causas $\mathrm{u}$ orígenes, que a continuación muestro y desarrollaré a continuación:

\footnotetext{
${ }^{\perp}$ Para citar este artículo: Valero Linero ED. La tributación en la cultura de los colombianos. RHS. Revista. Humanismo. Soc, Volumen 2 (1): 73-78.

*Autor para correspondencia: Edgar Daniel Valero Linero. Corporación Universitaria Remington. Calle 51 No 51-27, Edificio Remington. Facultad de Ciencias Empresariales. E-mail: edgardovalerolinero@yahoo.com.co.
} 
1. Poca enseñanza del tema en Instituciones educativas.

2. Corrupción de los funcionarios públicos.

3. Falta de vigilancia por parte de las entidades de control.

Los tres hechos anteriores, no solo suceden en Colombia, forma parte de una tradición y costumbres de muchos países latinoamericanos y países tercermundistas, pero este fenómeno no sucede con las mismas dimensiones e impacto en países como: Estados Unidos, Inglaterra, Alemania, Francia, Italia, Japón, debido al programa de concientización fiscal que le brindan a los niños desde la escuela o colegios y a los jóvenes desde las instituciones educativas en general, formando ciudadanos contribuyentes convencidos de su obligación moral de pagar los impuestos de manera justa, para retribuirlos en inversión social, programas de desarrollo, infraestructura, subsidiando a los más necesitados.

\section{Poca enseñanza del tema en centros educativos}

Los colegios y escuelas colombianos (Públicos y privados) dedican poco o nada de tiempo a enseñar y concientizar a sus alumnos, quienes serán futuros ciudadanos, futuros contribuyentes declarantes, o no declarantes, futuros funcionarios públicos, los conocimientos mínimos necesarios sobre el aspecto impositivo.

Es apenas obvio pensar que no se trata de impartir enseñanza sobre las normas mostradas en el Estatuto Tributario, lo importante es educar al ciudadano contribuyente desde niño para que pueda comprender desde su perspectiva las siguientes situaciones:

- La estructura del poder público en Colombia.

- La necesidad del recaudo de tributos y su destino.

- La responsabilidad de pagarlos en forma justa.

- El eficiente manejo que se debe dar a estos dineros.

- Las situaciones que se generan al no pagarlo, las consecuencias y sus sanciones.

Para que los ciudadanos en general de un país, puedan tener algún grado de educación tributaria, no es necesario que conozcan con profundidad y calidad las normas (Leyes - decretos - resoluciones) que la regulan, solo conocer los fines y objetivos de los impuestos, responsabilidad hacia su pago y sobre todo la credibilidad hacia los funcionarios públicos.

En Colombia las Facultades de Contaduría y Derecho, con relación a la Cátedra de Legislación Tributaria, persiguen como objetivo que el alumno interprete y desarrolle solo conocimientos técnicos de acuerdos a las distintas normas que van emitiendo los poderes públicos, agravando aún más el problema de formación.

El poder Legislativo colombiano emite leyes fiscales buscando los siguientes objetivos, entre otros:

- Incrementar los ingresos del estado a través de nuevos tributos, o el incremento de las tasas ya existentes.

- Brindar amnistías tributarias (Perdón y olvido).

- Beneficios de Auditoria para incrementar recaudo del impuesto de renta y acelerar la firmeza de las declaraciones tributarias.

- Frenar la evasión fiscal.

- Frenar el contrabando.

Pero en ningún momento busca ni fomenta la educación y concientización de los ciudadanos, a continuación cito algunos ejemplos, mostrando normas:

1. La reciente Reforma Tributaria (Ley 1607 de Diciembre de 2012), establece que los contribuyentes que al 26 de diciembre de 2012, hayan presentado demandas de nulidad que no haya sido emitida sentencia definitiva y aquellos a quienes antes de la fecha en mención se les haya notificado requerimiento especial, liquidación de revisión, liquidación de aforo o resolución podrán acogerse a conciliación o transacción del valor total de las sanciones e intereses, siempre y cuando pague el 100 $\%$ del impuesto discutido.

2. La misma ley indica que tratándose de deudas por periodos vencidos del año 2010 y anteriores, los contribuyentes podrán acceder a facilidades de pago, de la siguiente manera:

- Para pagos de contado, reducción del 80 \% de intereses de mora y sanciones.

- Para acuerdos de pagos, el $50 \%$ de los intereses de mora y sanciones. 
El espíritu del Legislador al crear o modificar amnistías es obtener ingresos y al mismo tiempo condonar deudas al contribuyente por concepto de intereses, quiere decir que, perdona y olvida hechos anómalos realizados con anterioridad por el mismo contribuyente. No hay acciones de formación, de educación ni concientización.

3. El artículo 689-1, del Estatuto Tributario, (Modificado por la Ley 1430 de 2010, en su artículo 33), establece un nuevo beneficio de Auditoria, donde induce o invita al contribuyente aumentar su impuesto de renta del año gravable 2012, en doce (12) veces la inflación del mismo año, con relación al impuesto neto de renta del 2011 y de esta manera su declaración de renta quedará en firme a los seis meses de su presentación oportuna.

También le brinda la alternativa de aumentar su impuesto de renta del 2012, siete veces la inflación del mismo año, con relación al año gravable 2011 y su declaración de renta del año gravable 2012, quedará en firme a los 12 meses de su presentación oportuna.

Esta norma demuestra que el objetivo es incrementar los ingresos, el contribuyente paga lo que el Legislador indica y los términos de firmeza de la declaración se reducen considerablemente.

No hay acción de formación ni culturización.

4. El artículo 657-1 del Estatuto Tributario indica que la policía fiscal y aduanera, creada por el artículo 77 de la ley 488, entre sus funciones, es solicitar o exigir al comprador, la factura expendida por el vendedor, en un radio hasta de 600 metros del local del vendedor.

El espíritu del Legislador, es evitar la omisión de ingresos por parte del vendedor, son medidas de orden policivo, pero no hay enseñanza en la formación de los ciudadanos.

5. La ley 488 de 1998, en su artículo 111, estableció amnistías para las declaraciones de renta ya presentadas, indicando que si son corregidas incrementando por lo menos, en un $30 \%$, el impuesto neto de renta, liquidado por el contribuyente, el término de firmeza de dichas declaraciones, será de cuatro meses, a partir de la fecha de vigencia de la presente ley, siempre y cuando pague en forma oportuna y total, el valor liquidado, incluido intereses.

El objetivo de la norma es incrementar el recaudo de impuestos, facilitándole al contribuyente corregir declaraciones ya presentadas, donde hubo hechos anómalos o irregularidades.

6. En el año 2005, mediante Resolución del Director de la Dian, nació la obligación para los contribuyentes de elaborar y enviar información exógena, sin embargo, desde 1989, algunos contribuyentes tenían la obligación de presentar información en medios magnéticos a la dirección de impuestos nacionales.

El objetivo de la información exógena es frenar la evasión, dificultar y minimizar las irregularidades en la Contabilidad, mediante el cruce de información con terceros.

Se ha podido observar y comprobar que los últimos proyectos de ley presentadas por el Ejecutivo, han sido aprobadas por el Legislativo en tiempo record, sin análisis de fondo y sin debates de altura, cuya causa se origina por la presión del ejecutivo, atropellando los principios constitucionales de los tributos.

Caso parecido sucedió en el 2012, con la reforma a la justicia, donde se votó favorablemente y fue reversada su decisión por la presión de los medios y el show mediático propiciado.

Podemos recordar también el proyecto de la reforma a la educación en el año 2011, proyecto de ley que se trabajó por lo menos un año, se presentó al Congreso y luego fue retirado y a la fecha no se ha realizado cambios a la educación.

Los ejemplos anteriores demuestran que las Reformas Tributarias:

- No obedecen a un estudio justificado de la situación económica del país.

- No se justifica con la política fiscal que se debe seguir.

- Se realizan para obtener ingresos a cualquier precio.

- Se realizan para minimizar la evasión.

- Para castigar los malos hábitos de los contribuyentes. 


\section{Corrupción de funcionarios públicos}

La falta de fundamentación educacional en el tema tratado, obnubila a los colombianos y cuando llegan a ser funcionarios públicos buscan el beneficio personal, obteniendo provecho con los dineros del Estado, en detrimento de la inversión, del beneficio social y colectivo, perdiéndose de esta manera, el objetivo y destino de los tributos recaudados, situación que contradice en todos sus aspectos la definición de impuestos y a sus principios constitucionales.

\section{Definición de impuestos}

Es una imposición pecuniaria impartida por el Estado, en cabeza del poder Legislativo (En circunstancias normales) y por el Ejecutivo en forma temporal (En estados de excepción, conmoción interna y emergencias sociales, económicas, que afecta a las personas naturales y jurídicas), siendo el Estado el sujeto activo del impuesto y el contribuyente el sujeto pasivo del impuesto.

El Estado invertirá los dineros recaudados por impuestos en beneficios sociales y comunitarios, lo que quiere decir que el Estado no está obligado a prestar servicios personales ni particulares.

En Colombia la definición de impuestos y los principios constitucionales solo existen en la teoría, en el trasegar de la vida de sus habitantes estos elementos no se dan, miremos algunos ejemplos de corrupción de los últimos años.

\section{Ejemplos de corrupción}

1. A mediados del año 2011, se descubrió un fraude realizados por funcionarios de la Dian, contra el Estado por más de $\$ 3.000 .000 .000$, situación que fue informada por el Presidente del país a través de medios televisivos, donde se comprobó que se habían realizado devoluciones injustificadas de impuestos, tanto de renta, como de impuesto sobre las ventas.

Para obviar su ocurrencia y reducir saldos considerables a favor del contribuyente, la Ley 1607 de 2012, en su artículo 42, que modifica el artículo 437-1 del Estatuto Tributario, disminuyó el porcentaje de retención en la fuente sobre el impuesto a las ventas, del $50 \%$ del impuesto, bajó al $15 \%$.

1. Teniendo Colombia tantos recursos naturales hay pobreza, miseria, desproporciones sociales, miremos el caso particular del Municipio de Condoto, (Chocó), donde hay gran cantidad de Oro y Platino y estos recursos son extraídos desde hace más de 80 años, el Municipio carece de agua potable y de infraestructura adecuada, el 90 \% de sus calles están sin pavimentar, las escuelas carecen de los elementos mínimos necesarios para generar un buen proceso de aprendizaje, muy a pesar que el Municipio recibe regalías de manera permanente.

2. Igualmente sucede en Muzo, (Boyacá), con el caso de las esmeraldas, donde pocos se enriquecen y el Municipio y su pueblo padecen de total pobreza.

3. Buenaventura el principal puerto marítimo de Colombia y existiendo Tratados De Libre Comercio aprobados con varios países, pero sus vías de acceso están totalmente deterioradas, el entrar o salir tanto del municipio como del puerto es totalmente traumático, a pesar que el municipio recibe de millonarias sumas de dinero solamente por peajes, (Tributo llamado tasa).

4. En Bogotá muchos ciudadanos se están quejando de la desproporción que tienen que pagar por obras de valorización de sus inmuebles, sin encontrar un organismo que los defienda basado en los principios constitucionales, como es la equidad y la progresividad. Es de tener presente que el pago de valorización es un tributo llamado Contribuciones.

5. El caso del cartel de la contratación en Bogotá, donde en su momento el propio Alcalde está preso por irregularidades en la contratación de obras públicas.

\section{Falta de vigilancia en las entidades de control}

La Constitución Nacional, en su artículo 117, establece y señala:

El Ministerio Público y la Contraloría General de la Republica son órganos de control. 
El artículo 268 de la constitución, indica entre otras, las siguientes atribuciones para la Contraloría:

1. Solicitar cuentas a los responsables del manejo de bienes o fondos de la nación.

2. Revisar las cuentas que deben llevar los responsables del manejo del erario público.

3. Establecer responsabilidades que se deriven de la gestión fiscal.

4. Conceptuar sobre la calidad y eficiencia de la gestión fiscal.

5. Promover y aportar pruebas, sobre investigaciones penales contra quienes han causado perjuicios a los intereses patrimoniales del Estado.

De acuerdo a la Constitución, la Contraloría deberá realizar sus controles en forma selectiva y posterior.

A pesar de las funciones citadas, la corrupción prima sobre los controles que pueda ejercer la contraloría y los dineros son malversados, sin que existan investigaciones de fondo, sanciones penales, sanciones disciplinarias o destituciones conocidas por la opinión pública, como muestra ejemplarizante de su labor de control.

En los últimos tres años se han observado algunas investigaciones de fondo $\mathrm{y}$ han penalizado a funcionarios públicos, como es el caso del cartel de la contratación en Bogotá, estas investigaciones han sido presionadas por los medios televisivos.

Considero que las pruebas de Auditoria que realiza la Contraloría sobre el manejo de los dineros públicos se deben realizar de manera total y previa, en lugar de ser pruebas selectivas y posteriores al hecho.

Las pruebas selectivas y posteriores aplican para países donde hay un desarrollo cultural impositivo y por consiguiente, los ciudadanos y funcionarios públicos tienen conductas transparentes en el pago y manejo de los tributos.

\section{Conclusiones}

La mayoría de los colombianos no creen en las personas que conforman los poderes públicos (Ejecutivo, Legislativo y Judicial), de hecho no le tienen confianza a los funcionarios públicos que manejan los dineros del erario público, tampoco confían en las instituciones de control y consideran que todas estas entidades pecan por omisión, negligencia, ineficiencia, incapacidad, o corrupción y el responsable principal es el Estado por no fomentar la cultura y la educación tributacional en sus ciudadanos, quienes buscan mecanismos de defensa de su dinero, para no tributar o para minimizar el pago de tributos, encontrando entre otras, las siguientes alternativas de evasión fiscal, ya sea persona natural o jurídica:

- Omisión de ingresos.

- Contrabando.

- Dumping.

- Omisión de activos.

- Declaración de pasivos inexistentes.

- Declaración de gastos no deducibles.

- Sobreestimación de costos.

\section{Sugerencias}

Es muy difícil dar sugerencias ante un mal que ha caracterizado la costumbre fiscal en Colombia, pero vale la pena tener en cuenta lo siguiente para minimizar en un alto porcentaje la actual situación cultural de los colombianos:

- Instituir, socializar y promover en el hogar, escuelas, colegios y universidades, una educación sana y pulcra relacionada con el tema en mención, para formar ciudadanos capaces de asumir responsabilidades en calidad de contribuyentes, ciudadanos capaces de manejar eficientemente los dineros del Estado y ciudadanos capaces de dirigir las entidades de control.

- Fortalecer las entidades de control en todos sus aspectos.

- La Contraloría debe volver a la figura del control previo y total.

- Penalizar con mayor rigurosidad los actos delictuosos cometidos por funcionarios públicos que atenten contra la inversión social. 
La puesta en marcha del proceso, traerá los siguientes beneficios:

1. Alto grado educacional y por ende ciudadanos dispuestos a pagar los impuestos que le corresponden.

2. Menos evasión fiscal.

3. Mayor recaudo de impuestos y mayor inversión social.

4. Menores gastos operativos en la DIAN, debido a que disminuiría los cobros coactivos, revisión de las liquidaciones privadas, disminución de visitas a las empresas, disminución de las revisiones de las importaciones.
5. Menos necesidades sociales.

6. Mejor infraestructura, mejor país, más oportunidades para los ciudadanos.

7. Simplificación de toda la normatividad fiscal.

\section{Referencias}

Los artículos citados han sido tomados fielmente del Estatuto Tributario Colombiano.

Los demás conceptos son opiniones personales. 